\title{
LA ESCUELA CHILENA BAJO LA DICTADURA CIVIL MILITAR (1973-1980): LA EXPERIENCIA ESCOLAR EN CONTEXTO AUTORITARIO ${ }^{\alpha}$
}

\author{
The Chilean school under the civil military dictatorship \\ (1973-1980): the school experience in authoritarian context
}

\section{Camila Pérez Navarro ${ }^{\circledR}$ y Felipe Zurita Garrido\%}

Fecha de recepción: 30/11/2020 • Fecha de aceptación: 18/03/2021

Resumen. Este artículo presenta los resultados de una investigación que tuvo como objetivo describir y analizar las transformaciones en la experiencia escolar a partir de las nuevas regulaciones diseñadas e implementadas por parte de la dictadura civil militar en Chile entre 1973 y 1980. Específicamente, se da cuenta de las iniciativas que buscaban controlar y vigilar a diversos actores del sistema educativo, transformar aspectos relevantes de la cultura escolar y reorientar las prácticas pedagógicas en la escuela. En términos metodológicos, se analizaron diversas fuentes primarias de tipo documental, como circulares, oficios y decretos-leyes publicados por el Ministerio de Educación; además de fuentes hemerográficas. Se concluye que estas acciones se orientaron a intervenir los establecimientos educativos en tres ámbitos principales: en la vida cotidiana escolar, mediante la incorporación e intensificación de nuevos ritos cívicos y religiosos; en la depuración e ideologización de los planes y programas educativos, y en las prácticas pedagógicas, a través del abordaje jerárquico de la relación entre docentes y estudiantes.

Palabras claves: escuela; experiencia escolar; dictadura civil militar; Chile.

\footnotetext{
a Artículo desarrollado en el contexto de implementación del proyecto FONDECYT de iniciación en investigación n. ${ }^{\circ} 11200265$ titulado: «Intelectuales en la construcción e implementación de la política educacional de la Dictadura Cívico-Militar en Chile (1973-1990): trayectorias biográficas de ministros de educación, subsecretarios de educación y directores del CPEIP», cuyo investigador responsable es Felipe Zurita. Autores agradecen a las/os revisores por sus valiosos comentarios.

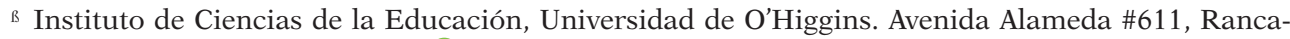
gua, Chile. camila.perez@uoh.cl (D) https://orcid.org/0000-0003-0372-1121

y Departamento de Educación Básica, Universidad Metropolitana de Ciencias de la Educación. Avenida José Pedro Alessandri \#774, Ñuñoa, Chile. felipe.zurita@umce.cl (iD https://orcid.org/0000-0002-4136-4340
}

Cómo citar este artículo: Pérez Navarro, Camila y Felipe Zurita Garrido. «La escuela chilena bajo la dictadura civil militar (1973-1980): la experiencia escolar en contexto autoritario». Historia y Memoria de la Educación 14 (2021): 587-614 
Abstract. This paper presents the results of an investigation that aimed to describe and analyse the transformations in the educational experience of students and teachers based on the new regulations designed and implemented by the civil-military dictatorship in Chile between 1973 and 1980. Specifically, it deals with the initiatives that sought to control and monitor various actors in the educational system at different levels and to transform relevant aspects of school culture and reorient pedagogical practices in the school. In methodological terms, various primary documentary sources were analysed, such as circulars, official letters and decree-laws published by the Ministry of Education, newspapers, and magazines. We conclude that these actions were aimed at intervening educational establishments in three main areas: in daily school life, through the incorporation and intensification of new civic and religious rites; in the purification and ideologization of educational plans and programs, and in pedagogical practices, through a hierarchical approach to the relationship between teachers and students.

Keywords: school; educational experience; civil military dictatorship; Chile.

\section{INTRODUCCIÓN}

Las transformaciones desarrolladas en los sistemas educacionales en el contexto de gobiernos dictatoriales han concitado el interés de múltiples investigadoras e investigadores a nivel internacional. Estos estudios se han interesado en explorar las innovaciones al nivel de las políticas educacionales, los impactos en la cultura escolar, la elaboración e instauración de teorías y filosofías conservadoras en la formación de las nuevas generaciones, la violencia política contra las y los actores educativos, entre muchos otros temas. Este interés ha sido más visible en países que han atravesado recientemente experiencias dictatoriales, tales como Argentina, ${ }^{1}$ Brasil, ${ }^{2}$

\footnotetext{
1 Juan Carlos Tedesco, Cecilia Braslavsky y Ricardo Carciofi, El proyecto educativo autoritario (19761982) (Buenos Aires: FLACSO, 1985); Carolina Kaufmann (Dir.), Dictadura y Educación. Tomo I. Universidad y Grupos Académicos (1976-1983) (Buenos Aires: Miño y Dávila, 2001); Carolina Kaufmann (Dir.), Dictadura y Educación. Tomo II. Depuración y vigilancia en las Universidades Nacionales Argentinas (Buenos Aires: Miño y Dávila, 2003); Carolina Kaufmann (Dir.), Dictadura y Educación. Tomo III. Los textos escolares en la historia argentina reciente (Buenos Aires: Miño y Dávila, 2006); Pablo Pineau, Marcelo Mariño, Nicolás Arata y Belén Mercado, El principio del Fin. Políticas y Memorias de la educación en la última dictadura militar (1976-1983) (Buenos Aires: Editorial Colihue, 2006); Pablo Pineau, «Reprimir y discriminar. La educación en la última dictadura cívico-militar en Argentina (1976-1983)», Educar em Revista 30, no. 51 (2014): 103-122. https://doi.org/10.1590/S010440602014000100008

2 Dermeval Saviani, «O legado educacional do regime militar», Cadernos CEDES 28, no. 76 (2008): 291 312. https://dx.doi.org/10.1590/S0101-32622008000300002; Rodrigo Patto Sá Motta, As universidades e o
} 
España, ${ }^{3}$ Italia ${ }^{4}$ y Portugal, ${ }^{5}$ lo que ha hecho que el estudio de sus pasados conflictivos sea una tarea necesaria para proyectar formas de organización de sus sistemas educativos adecuadas a un contexto democrático. En el caso de Chile, el estudio de las transformaciones en el sistema educacional implementadas por la dictadura civil militar (1973-1990) ha tenido un interesante desarrollo, siendo posible identificar relevantes trabajos publicados durante el mismo periodo autoritario, como así también otras investigaciones realizadas con posterioridad. De forma general, el interés de las y los investigadores ha estado situado en el estudio de las políticas educacionales diseñadas e implementadas por la dictadura, tanto desde una perspectiva general ${ }^{6}$ como así también focalizando el análisis sobre iniciativas en torno a problemas específicos (por ejemplo, la influencia del modelo

regime militar. Cultura política brasileira e modernização autoritária (Rio de Janeiro: Zahar, 2014); Odair Sass, Carlos Antonio Giovinazzo Júnior, Domenica Martinez, Helenice Ciampi, Leda Maria de Oliveira Rodrigues y Maria Amelia Güllnitz Zampronha, Educação e Regimes Ditatoriais: 50 anos do Golpe Militar no Brasil (Araquara: Junqueira\&Marin, 2018); Marcus Aurelio Taborda de Oliveira, Educação Física Escolar e Ditadura Civil-Militar no Brasil (1968-1984): Entre a Adesão e a Resistência e Outros Estudos (Curitiba: Editora UFPR, 2018).

3 Ramón Navarro Sandalinas y Manuel Tuñón de Lara, La enseñanza primaria durante el franquismo (1936-1975) (Barcelona: PPU, 1990); Antonio Viñao Frago, «La educación en el franquismo (19361975)», Educar em Revista 30, no. 51, 19-35. https://doi.org/10.1590/S0104-40602014000100003; Julio Antonio Yanes Mesa, «La propaganda, el entretenimiento y la educación en los espacios infantiles de la radiodifusión de las Islas Canarias durante el franquismo, 1939-1975», Historia y Memoria de la Educación 4 (2016); 371-392. https://doi.org/10.5944/hme.4.2016.16226; Carlos Sanz Simón, «Los símbolos del nacionalcatolicismo. Una mirada a través de la fotografía escolar durante la dictadura franquista (1950-1959)», Historia y Memoria de la Educación 10 (2019): 409-449. https:// doi.org/10.5944/hme.10.2019.22194

4 Maria Cristina Morandini, «I quaderni di epoca fascista veicolo di propaganda ideologica e strumento didattico: il fondo della scuola elementare Parini di Torino (1938-1942)", Historia y Memoria de la Educación 10 (2019): 383-408. https://doi.org/10.5944/hme.10.2019.23365; Octavio Spindola Zago, "Hemos hecho Italia, ahora tenemos que hacer a los italianos". El aparato educativo transnacional del régimen fascista italiano, 1922-1945», Historia Mexicana 69, no. 3 (2020): 1189-1246._https://doi.org/10.24201/hm.v69i3.4021_

\footnotetext{
5 Antonio Gomes Ferreira y Luís Mota, «Diferentes perspetivas de um ensino conservador: o ensino liceal em Portugal durante o Estado Novo (1936-1960)», Educar em Revista 30, no. 51 (2014): 145174. https://doi.org/10.1590/S0104-40602014000100010; Maria Paula Pereira, «A Escola Portuguesa ao serviço do Estado Novo: as Lições de História de Portugal do Boletim do Ensino Primário Oficial e o Projeto Ideológico do Salazarismo», Da Investigação às Práticas 4, no. 1 (2014): 59-81; Carlos Alberto Magalhães Gomes Mota, «A Educação Portuguesa durante o Estado Novo (1933-1974): uma visão de síntese», Saberes Interdisciplinares 13, no. 25 (2020): 33-48._http://186.194.210.79:8090/revistas/index.php/SaberesInterdisciplinares/article/view/340_

6 Programa Interdisciplinario de Investigación en Educación, Las Transformaciones Educacionales bajo el Régimen Militar (Santiago: PIIE, 1984); Carlos Ruiz, De la República al mercado. Ideas educacionales y política en Chile (Santiago: LOM, 2010).
} 
económico neoliberal en dichas políticas educacionales, ${ }^{7}$ la violencia política dirigida por agentes del régimen contra diferentes actores educativos, ${ }^{8}$ las formas de organización y resistencia del profesorado, ${ }^{9}$ las transformaciones desarrolladas en el trabajo docente, ${ }^{10}$ entre otros).

Sin embargo, las transformaciones más específicas vinculadas a la experiencia educativa de estudiantes y docentes al interior del sistema educativo han sido poco exploradas por parte de las y los investigadores, ${ }^{11}$ probablemente a causa de problemas de acceso a los archivos. Con el objetivo de realizar un aporte a esta área de investigación no suficientemente explorada, el presente trabajo busca analizar las transformaciones en la experiencia escolar, a partir de las diferentes regulaciones diseñadas e implementadas por parte de las autoridades educacionales de la dictadura. Es importante considerar que algunas orientaciones de estas transformaciones y regulaciones no necesariamente son creaciones originales de la dictadura, sino que corresponden a procesos de rearticulación de fenómenos de larga data en la historia educacional de Chile. Tal

\footnotetext{
7 Camila Pérez y Andrés Rojas-Murphy, «Introducción y consolidación de los principios de mercado en el discurso oficial sobre educación de la dictadura civil militar chilena (1973-1990)», Paulo Freire. Revista de Pedagogía Crítica 20 (2019): 105-122. https://doi.org/10.25074/07195532.20.1089

8 Martín Faunes, Aulas que permanecerán vacías (Santiago: Cuarto Propio, 2008); Pamela Sánchez, Una asignatura pendiente: profesores y profesoras detenido/as, desparecido/as y ejecutado/as en Chile de 1973 a 1990 (Santiago: ARCIS, 2013); Felipe Zurita, «Represión y vigilancia hacia el Trabajo Docente durante la Dictadura Militar en Chile (1973-1990)», Araucaria. Revista Iberoamericana de Filosofía, Política y Humanidades 38 (2017): 285-322. https://doi.org/10.12795/araucaria.2017.i38.13

9 Leonora Reyes, «Movimientos de educadores y construcción de política educacional en Chile» (Tesis para optar al grado de doctora en Historia, Universidad de Chile, 2005).

10 Felipe Zurita, «El trabajo docente durante la Dictadura Cívico-Militar en Chile (1973-1990): una mirada desde las políticas públicas educacionales», Revista História da Educação 24 (2020): 1-31. https://doi.org/10.1590/2236-3459/92711; Felipe Zurita, «El trabajo docente bajo sospecha los límites a las prácticas docentes en las Políticas Públicas Educacionales de la Dictadura Cívico Militar en Chile (1973-1990)», Educació i Història: Revista d'Història de l'Educació 35 (2020): 207-227. https:// doi.org/10.2436/20.3009.01.243
}

11 Véase, por ejemplo, Camila Pérez Navarro, «El control de las escuelas durante la Dictadura Cívico Militar chilena: el caso de la Escuela Experimental de Niñas de Santiago», Anuario de Historia de la Educación 18, no. 2 (2017): 5-25; Camila Pérez Navarro, «La intervención de las escuelas durante las dictaduras cívico-militares en el Cono Sur. Miradas desde la historia de la educación», en Latinoamérica: la educación y su historia. Nuevos enfoques para su debate y enseñanza, coords. Nicolás Arata y Pablo Pineau (Buenos Aires: Editorial de la Facultad de Filosofía y Letras, UBA, 2019), 423-449; Javiera Errázuriz, «Control y disciplinamiento de la comunidad estudiantil en los primeros años del régimen militar (1973-1975): Los expedientes de Geografía y Teatro en la Universidad de Chile», Cuadernos Chilenos de Historia de la Educación 8 (2017): 36-56. http://historiadelaeducacion.cl/index.php/CCHE/article/view/9 
es el caso del nacionalismo educacional que ha sido articulado de diferentes maneras y con diferentes objetivos en momentos específicos de la historia educacional chilena. ${ }^{12}$

Por experiencia escolar entendemos a aquellas diversas normas y prácticas que organizan la vida de estudiantes y docentes en las escuelas, las que, al mismo tiempo, se constituyen en las características específicas de la forma escolar de educación, por ejemplo: el diálogo que estudiantes y docentes llevan adelante con símbolos y dispositivos culturales que les permiten organizar su entendimiento de la experiencia en la escuela, las formas más aceptadas de llevar adelante los roles de enseñante y aprendiz, la articulación de sus actividades con objetivos y finalidades mayores que exceden al espacio escolar, entre otras. ${ }^{13}$

Específicamente, y siguiendo lo planteado por algunos autores, ${ }^{14}$ esta investigación analiza el primer período de la dictadura. Esta primera fase comprende los días posteriores al Golpe de Estado de septiembre de 1973 hasta inicios de la década de 1980, y se caracteriza por el énfasis en la depuración de la enseñanza y el control de las instituciones educativas por parte de las Fuerzas Armadas. El nombramiento de Contraalmirantes como ministros de Educación Pública entre 1973 y 1978 revela la preocupación de la Junta Militar por controlar el sistema escolar. ${ }^{15}$

\footnotetext{
12 Algunas de las investigaciones que abordan de forma directa o indirecta la relación entre nacionalismo y educación en Chile a fines del siglo XIX y principios del siglo XX son las siguientes: Patrick Barr-Melej, Reforming Chile: Nationalism, and the Rise of the Middle Class (Chapel Hill: University of North Carolina Press, 2001); Sergio González Miranda, Chilenizando a Tunupa. La escuela pública en el Tarapacá andino 1880-1990 (Santiago: DIBAM, 2002); Stefan Rinke, Cultura de masas, reforma y nacionalismo en Chile 1910-1931 (Santiago: DIBAM, 2002); Jorge Rojas Flores, Moral y prácticas cívicas en los niños chilenos, 1880-1950 (Santiago: Ariadna Ediciones, 2004); Jorge Rojas Flores, Historia de la infancia en el Chile republicano: 1810-2010 (Santiago: JUNJI, 2010); Pablo Toro-Blanco, " "Como se quiere a la madre o a la bandera: Notas sobre nacionalismo, ciudadanía y civilidad en la educación chilena (1910-1945)”», en Nacionalismos e identidad nacional en Chile. Siglo XX. Volumen I, ed. Gabriel Cid y Alejandro San Francisco (Santiago: Ediciones Bicentenario, 2010), 133-158; Stefan Rinke, Encuentros con el Yanqui. Norteamericanización y cambio sociocultural en Chile (18981990) (Santiago: DIBAM/LOM, 2014); Pablo Toro Blanco, “ “iNiños, seamos buenos, miremos ese horror!". El nacionalismo cívico como régimen emocional en la educación chilena durante la segunda guerra mundial (c.1941-c.1945)», Sarmiento. Revista Galego-Portuguesa de Historia da Educación 24 (2020): 161-175.

13 Dominique Julia, «A Cultura Escolar como Objeto Histórico», Revista Brasileira de História da Educação 1 (2001): 9-43.

14 Programa Interdisciplinario, Las Transformaciones Educacionales; Pérez Navarro, «El control de las escuelas».

15 Pérez Navarro, «El control de las escuelas».
} 
En términos metodológicos, se desarrolló un trabajo de orientación historiográfica organizado en base a la revisión y análisis de fuentes primarias de dos tipos. Por un lado, fueron catastradas cerca de 300 circulares enviadas por el Gabinete del ministro de Educación Pública y la Dirección de Educación Secundaria a liceos durante el período de estudio; documentos que fueron consultados en el archivo escolar del Liceo n. 1 Javiera Carrera de Santiago. La decisión de trabajar con estas fuentes radica en que estas circulares fueron las enviadas por la dictadura directamente a los liceos para normalizar la vida cotidiana escolar e intervenir los establecimientos educativos. De este total, fueron analizadas en profundidad aproximadamente 35 circulares referidas principalmente al funcionamiento de los establecimientos educacionales, tanto a nivel curricular, de prácticas pedagógicas como a normas de comportamiento de profesores y estudiantes. Asimismo, el corpus documental estuvo conformado por todas las actas de las sesiones secretas de la Junta Militar relativas a la temática, las cuales se encuentran disponibles en la Biblioteca del Congreso Nacional; y aquellos oficios y decretos-leyes disponibles en el Fondo del Ministerio de Educación Pública del Archivo Nacional de la Administración. De estos, es necesario destacar que solo fueron analizados aquellos relacionados explícitamente con la intervención del espacio escolar. Complementariamente, se revisaron fuentes de tipo hemerográfico, como el periódico El Mercurio, portavoz oficial de la dictadura.

Las fuentes fueron examinadas a partir del análisis del contenido de la documentación, con base en categorías definidas a partir de las siguientes interrogantes: ¿Qué caracterizó a la experiencia de asistir a la escuela chilena después del Golpe de Estado de septiembre de 1973? ¿Qué valores y dispositivos privilegió la dictadura para estructurar la experiencia escolar de estudiantes y profesores al interior de la escuela? Las familias de categorías analizadas fueron: normas, símbolos y valores patrios, disciplina, contenidos, rituales.

Estas fuentes permitieron reconstruir una compleja red de decisiones y orientaciones emanadas desde las autoridades educacionales dirigidas a regular la experiencia de aquellas y aquellos agentes que habitaban el espacio escolar. Si bien la literatura muestra la tensión y pugna entre dos orientaciones reformistas por parte de los funcionarios civiles y militares de la dictadura -los primeros, empecinados en transformar 
radicalmente el sistema educativo con base en principios de carácter neoliberal; los segundos, empeñados en mantener el Estado Docente en su forma mínima-;16 en este artículo se evidencia que durante los primeros años de la dictadura la intervención de las escuelas fue intensa, lo que se explica, en parte, a la fuerte presencia de militares en el Ministerio de Educación Pública y en otras carteras ministeriales.

Para dar cuenta de lo anterior, el artículo está organizado en tres secciones. En la primera parte se analizan las transformaciones desarrolladas en el sistema escolar con posterioridad al Golpe de Estado, destacando las iniciativas desplegadas por la dictadura para controlar al sistema educativo. En la segunda sección se analizan los componentes organizadores de la experiencia escolar bajo el régimen autoritario, con especial interés en la valoración del disciplinamiento y los valores patrios a través de diversos dispositivos escolares. En la tercera y última sección se proponen conclusiones a partir del análisis transitado.

\section{LAS ESCUELAS TRAS EL GOLPE}

El día que ocurrió el Golpe de Estado, el 11 de septiembre de 1973, en las escuelas y liceos chilenos se celebraría el Día del maestro, tal como era tradición desde hace tres décadas en algunos países latinoamericanos. Probablemente, estudiantes y apoderados realizarían homenajes a sus profesores. En el Teatro Municipal de Santiago, el Ministerio de Educación Pública efectuaría un acto con el objetivo de distinguir y premiar a todos los profesores que cumplían 35 o más años de servicio. ${ }^{17} \mathrm{La}$ intervención militar en el Palacio de la Moneda obligó a suspender toda celebración escolar.

La llegada de los militares al poder alteró fuertemente la cotidianeidad de escuelas y liceos. Con base en la Doctrina de Seguridad Nacional, las Fuerzas Armadas, al tomar control de los establecimientos educacionales y recintos universitarios, ordenaron nuevas normas de comportamiento a

\footnotetext{
16 José Joaquín Brunner, La cultura autoritaria en Chile (Santiago de Chile: Facultad Latinoamericana de Ciencias Sociales, 1981); Camila Pérez Navarro, «Reconstrucción del proceso de elaboración de la Ley Orgánica Constitucional de Enseñanza: actores, proyectos y disputas ideológicas. Chile, 1973-1990», Espacio, Tiempo y Educación 5 (2018), 179-195.

17 Ministerio de Educación Pública, Dirección de Educación Primaria y Normal, Dirección de Educación Secundaria, Dirección de Educación Profesional, Circular no. 73-57-75, 13 de agosto de 1973, p. 1.
} 
actores educativos, iniciaron un proceso de limpieza ideológica en planes y programas de enseñanza, se implementaron nuevos rituales escolares y se intentó depurar el sistema educativo, eliminando todos aquellos 'elementos' que tuvieran alguna orientación marxista. Asimismo, se revitalizaron prácticas pedagógicas tradicionales, como la memorización, el dictado y la verticalidad de la relación entre docentes y estudiantes, las cuales habían sido el objeto de cambio de la política educacional de los gobiernos liderados por la Democracia Cristiana y la Unidad Popular entre 1964 y 1973.

\section{La intervención de las instituciones educativas}

De acuerdo con las nuevas autoridades, la infiltración de la ideología marxista en los establecimientos educacionales había provocado una severa crisis en el sistema, la cual se evidenciaba en que «los establecimientos escolares básicos y medios, así como las Escuelas Normales, estaban semiparalizadas (desde hacía dos meses), teniendo un funcionamiento muy irregular a lo largo del año con paros, tomas y enfrentamientos». ${ }^{18}$ Frente a esta situación, se determinó mantener las clases suspendidas hasta que la situación en escuelas, liceos y universidades se normalizara, ${ }^{19}$ mientras se hizo un llamado a los estudiantes a:

dedicarse a sus estudios, eliminándose cualquier tipo de asociaciones o federaciones. No se aceptarán huelgas o paros y aquellos que sean detenidos por aquellas circunstancias, serán destinados a cuarteles de la FF.AA. o Carabineros a efectuar un período de instrucción militar. ${ }^{20}$

En la misma línea, la profesora Irma Saavedra Molina -designada Directora de Educación Secundaria- instaba a los estudiantes a alejarse de la política contingente, señalando que tenía «la imperiosa obligación de dar lo mejor de nuestros esfuerzos y toda nuestra dedicación para que las labores escolares se realicen en su integridad, sin prejuicios y sin

\footnotetext{
18 Chile, Augusto Pinochet Ugarte, Un año de construcción. 11 de septiembre 1973 - 11 de septiembre 1974: el Jefe Supremo de la nación General de Ejército Augusto Pinochet Ugarte informa al país (Santiago: s. n., 1974), 267 - 268.

19 Gonzalo Vial, «Entrevista a Ministro de Educación», El Mercurio, 8 de marzo, 1979, p. 10.

20 Acta de la Sesión Secreta no. 1 de la Junta de Gobierno, 13 de septiembre de 1973.
} 
que las pasiones políticas nos perturben en esta finalidad tan noble como es la de educar a la juventud».21

En los años posteriores al Golpe de Estado, el control de las instituciones continuó siendo intenso. La restricción constitucional del derecho de reunión se mantuvo durante dos meses, derivando en la prohibición de realizar reuniones de padres y apoderados.22 Además, se determinó la suspensión de las funciones de todos los Centros de Alumnos. Mediante la difusión de las circulares no. 668, del 11 de julio y no. 93, del 6 de agosto, las Fuerzas Armadas notificaron que los Centros de Padres y Centros de Alumnos

no deberán intervenir en materias de orden político y religioso ni aquellas que se relacionan con la organización técnica, las prácticas pedagógicas y el régimen administrativo y disciplinario de los establecimientos, ni adoptar decisiones que en cualquier forma desvirtúen el cumplimiento de sus finalidades. ${ }^{23}$

Durante los meses siguientes, las instituciones educativas se encontraron sitiadas, se encarceló, torturó, exilió y asesinó a profesores y estudiantes militantes de partidos de izquierda, ${ }^{24}$ y las organizaciones sindicales de docentes fueron desarmadas. Paralelamente a los cambios que se implementaban a nivel institucional y burocrático, se registraban las detenciones de estudiantes secundarios y de profesores ligados al proyecto político de la Unidad Popular. Rosa Gutiérrez, estudiante del Liceo no. 1 de Niñas de Valparaíso, cursaba 4. ${ }^{\circ}$ Año Medio cuando las Fuerzas Armadas llevaron a cabo el Golpe. Rosa, quien había colaborado activamente con el gobierno de Salvador Allende en su rol de militante de las Juventudes Comunistas y como presidenta del Centro de Estudiantes, experimentó la represión y fue parte de una realidad educacional trastornada por los cambios políticos:

\footnotetext{
21 Ministerio de Educación Pública, Dirección de Educación Secundaria, Circular no. 1, 26 de septiembre de 1973.

22 Circular no. 33, difundida por la Dirección de Educación Secundaria el día 29 de noviembre de 1973.

23 Ministerio de Educación Pública, Circular no. 668, 11 de julio de 1974.

$24 \mathrm{Al}$ respecto, ver el libro de Sánchez, Una asignatura pendiente, en el cual se recopilan e investigan 134 casos de profesores víctimas de la Dictadura Militar.
} 
al regresar del Liceo, encuentro que mi casa estaba siendo allanada. Uno de mis hermanos, que me esperaba a los pies del cerro, me dijo que no regresara porque habían preguntado por mí. Días después, estando yo en el Liceo, dos marinos me entraron a buscar a la sala de clases y me llevaron a una Escuela en la cual había varios dirigentes estudiantiles. Como una consigna no premeditada, nosotros no nos hablábamos. Un Oficial de la Marina me interrogó acerca de cuántas células comunistas funcionaban en mi Liceo, como eso no se confiaba a nadie me negué y desconocí el hecho. Un par de cachetadas fueron mi primer enfrentamiento con la realidad. Yo no sabía ante quienes me enfrentaba. Tenía 17 años. ${ }^{25}$

Estudiantes, profesores, funcionarios y apoderados fueron objeto de la limpieza ideológica del sistema educacional por parte de las Fuerzas Armadas. Para iniciar la fundación de un «nuevo Chile», la Junta de Gobierno separó de las escuelas y liceos a todos aquellos elementos considerados "peligrosos», y se procuró que los funcionarios que continuaban prestando servicios al Estado no estuvieran ligados a grupos opositores. De acuerdo con el acta de la sesión secreta del 8 de octubre de 1974, el Ministro de Educación Contraalmirante Hugo Castro Jiménez declaró el apoyo de la Dirección de Inteligencia Nacional (DINA) y de las Fuerzas Armadas en el proceso de depuración del sistema educativo, señalando que

la Inteligencia está permanentemente funcionando, dando datos, indicando que hay que sacar a determinado profesor, que hay que poner a otro, etc. El Ejército coopera mucho; Carabineros en menor escala; la Armada y la FACH también tienen delegados y en algunas provincias más cantidad de gente que el Ejército; pero el Ejército a través de los Intendentes influye bastante. ${ }^{26}$

\footnotetext{
25 Es importante destacar que, debido a su buen rendimiento académico, Rosa quedó seleccionada en la carrera de Medicina en la Universidad de Concepción, pero una tercera detención implicó que abandonara el país en septiembre de 1974. En: Proyecto Internacional de Derechos Humanos (20002012), «"Yo acuso a Pinochet”. Testimonio de Rosa Gutiérrez Silva». Archivo digital de las Violaciones a los Derechos Humanos en la Dictadura Militar en Chile (1973-1990). Londres. Recuperado de: http:// www.memoriaviva.com/testimonios/Testimonio_de_Rosa_Gutierrez_Silva.htm
}

26 Acta de la Sesión Secreta no. 160 de la Junta Militar, 8 de agosto de 1974, p. 2. 
El control de las escuelas por las Fuerzas Armadas continuó fuertemente durante los años siguientes al Golpe Militar, teniendo atribuciones como visitar los establecimientos educacionales a cualquier hora, fiscalizar el cumplimiento de los horarios de clases, citar al director o profesores a declarar a la Unidad Militar correspondiente, caducar contratos a funcionarios de escuelas y liceos y asistir a reuniones de padres y apoderados o, incluso, suspenderlas. La Circular n. ${ }^{\circ} 1012$ explicitaba las funciones extraordinarias que podían atribuirse los representantes de las Fuerzas Armadas y Carabineros en las zonas que se encontraban en Estado de Emergencia. Este documento sumaba a las atribuciones de coordinación, información, fiscalización y control, la facultad de intervenir el personal administrativo de los servicios públicos, solicitando renuncias, exonerando, suspendiendo y designando reemplazantes. ${ }^{27}$

Adicionalmente, en agosto de 1974, una Circular difundida por el Comando de Institutos Militares del Ejército -organización encargada del sistema educacional en Santiago- reiteraba la importancia de la intervención de las Fuerzas Armadas en el «saneamiento y control del funcionamiento del Área de la Educación», y establecía las prácticas prohibidas en las escuelas, como

Comentarios sobre política contingente; Propagación de rumores mal intencionados sobre actividades de Gobierno o Grupos Extremistas; Distorsión de los conceptos o Valores Patrios; Distorsión de las ideas contenidas en los Textos de Estudio, dándoles interpretaciones antojadizas parciales [...] No acatamiento de las disposiciones emanadas del Ministerio de Educación o de la Autoridad Militar en forma rápida y efectiva, especialmente aquellas relacionadas con la exaltación de valores patrios; Propagación de ideas tendientes a forzar al Director a autorizar la creación de organismos no autorizados, mediante sistemas de votaciones directas; Cualquier otro antecedente o hecho que demuestre claramente tendencia a interrumpir, dificultar, frenar, distorsionar, dislocar, minar la disciplina o alterar el normal desarrollo de las actividades educativas en los alumnos, a todo nivel $[\ldots] .28$

\footnotetext{
27 Ministerio de Educación, Circular no. 1012, 14 de junio de 1974, p. 6.

28 Ejército de Chile. Comando de Institutos Militares, Circular para regular el funcionamiento de los establecimientos educacionales del Gran Santiago. Santiago, 12 de agosto de 1974, pp. 3-4.
} 
Cualquier actividad de funcionarios, profesores o personal administrativo que estuviera fuera de los límites señalados por las autoridades militares debía ser denunciada directamente al Comando de Institutos Militares, actuando con «reserva, tino y criterio, para evitar crear un ambiente de agitación, nerviosismo o temor entre los educandos». ${ }^{29}$ Según establecía la Circular, toda omisión sería de exclusiva responsabilidad del director del establecimiento educacional.

\section{Depuración de los contenidos escolares y la ideologización de la enseñanza}

El control del sistema educativo por parte de las Fuerzas Armadas no afectó únicamente el funcionamiento de las escuelas y a la vida cotidiana de estudiantes y profesores, sino que también fueron modificados los contenidos que estaban siendo enseñados en los liceos y retirados los textos escolares que habían sido distribuidos por el Ministerio de Educación Pública durante el gobierno de la Unidad Popular. Al respecto, dos semanas después del Golpe de Estado, el Director de Educación Primaria y Normal Carlos Hormazábal señalaba en una entrevista que «los textos concientizadores están siendo retirados de la circulación en los colegios, con el objeto de quemarlos. No podemos permitir que al alumno se le envenene la mente con textos que nada bueno conducen».30 Durante los meses de septiembre y octubre las Fuerzas Armadas realizaron una completa «limpieza» de la cultura material de las escuelas, solicitando los muebles e inmuebles que habían pertenecido a los partidos políticos declarados ilegales, ${ }^{31}$ y la devolución de libros que habían sido donados a establecimientos educacionales por la Editorial Quimantú durante el gobierno de la Unidad Popular. Textos como «La lucha por la tierra», «Así trabajo yo», «Historia de las poblaciones callampas» o «Yo vi nacer y morir los pueblos salitreros» debían ser obligatoriamente devueltos a brevedad por los directores al Ministerio de Educación Pública. ${ }^{32}$

\footnotetext{
29 Ejército de Chile, Circular para regular, p. 4.

30 «Director de Educación Primaria: Recuperación de clases se hará con el máximo apoyo del profesorado», El Mercurio, 25 de septiembre, 1973, p. 10.

31 Ministerio de Educación, Dirección de Educación Secundaria, Circular no. 32, 24 de noviembre de 1973.

32 Ministerio de Educación, Dirección de Educación Secundaria, Circular no. 19, 31 de octubre de 1973.
} 
Según lo señalado en El Mercurio, en octubre de 1973 la Junta de Gobierno inició la censura del currículo escolar vigente para la educación secundaria, con el propósito de eliminar aquellos «contenidos concientizadores» introducidos por el gobierno de la Unidad Popular:

El proyecto de mayor envergadura fue la ENU, pero desde mucho antes los ideólogos de la Unidad Popular habían obtenido la introducción en los programas de conceptos políticos en referencia a la valoración de la cultura y las instituciones del país, así como de visiones marxistas de la historia nacional, de la de los demás pueblos latinoamericanos y de la historia de la cultura en general. ${ }^{33}$

Las medidas adoptadas por la Junta Militar tenían un carácter provisorio, hasta que se formularan nuevos programas para la enseñanza básica y media. Al respecto, el Ministro de Educación Pública señalaba en la ceremonia de inauguración del año escolar 1974 que uno de los principales cambios implementados en el nuevo período lectivo radicaba en que «los planes de estudios vigentes hasta 1973 han sido reemplazados por otros que, con el carácter de transitorios, se aplicarán durante 1974. Las mayores innovaciones en los mismos afectan las asignaturas de Ciencias Sociales, Filosofía y Castellano». ${ }^{34}$ Los nuevos planes enfatizaban fuertemente los contenidos relacionados con la historia nacional. A modo de ejemplo: de acuerdo con lo expuesto en el documento Programas de Estudios de Educación Enseñanza Media. Ciencias Sociales e Historia y Geografía de Chile, Tercero y cuarto año, publicados por el Ministerio de Educación Pública en 1978, uno de los objetivos generales de la unidad titulada «Introducción a la vida cívica» era «acentuar en la formación de los adolescentes y jóvenes la conciencia patriótica y la conciencia humanista». Para esto último, se recomendaba realizar actividades como "sintetizar rasgos biográficos de las personalidades que integran el actual Consejo de Estado», «Lectura y comentario del pensamiento político de grandes hombres del país como O’Higgins, Portales, M. Montt, Balmaceda, A. Alessandri». Al respecto, el investigador Pablo Toro-Blanco evidenció, ${ }^{35}$ con base

\footnotetext{
33 «Ciencias Sociales», El Mercurio, 20 de octubre, 1973.

34 «Comienza el año escolar», El Mercurio, 11 de marzo, 1974, portada y p. 12.

35 Pablo Toro-Blanco, «Towards a new Chile through the heart: aspects on the construction of a nationalist emotionology in school textbooks during Pinochet years (c.1974-c.1984)», History of Education \& Children's Literature X, 1 (2015), 583-600.
} 
en el análisis de los textos escolares utilizados en las escuelas durante la dictadura, el énfasis nacionalista y apelaciones de carácter emotivo en la enseñanza de la historia y ciencias sociales.

La medida de censura sobre contenidos y referencias a otras naciones se extendía también a la exhibición de símbolos extranjeros en la escuela. A través de la Orden Ministerial Permanente no. 1, el Ministerio de Educación Pública estableció que los directores debían «abstenerse de exhibir en sitios públicos, incluidos los salones, salas de clases, comedores y patios, símbolos extranjeros y retratos o efigies de personajes o gobernantes extranjeros», mientras que aquellos establecimientos educacionales que llevaban nombres de países debían solicitar un permiso especial a la Intendencia o Gobernación respectiva para conmemorar cualquier efeméride ajena a Chile. De la misma forma, quedaba terminantemente prohibido izar la bandera chilena junto con banderas de otras naciones, así como también portar insignias o distintivos que «representen nacionalidades extranjeras o regímenes o ideologías políticas nacionales o extranjeras». Asimismo, se sumaron nuevos temas, enfatizando aquellos contenidos que tenían relación con símbolos y héroes patrios. De acuerdo con el proyecto de la primera Orden Ministerial Permanente emitida los días posteriores al Golpe Militar, los directores y funcionarios de establecimientos educacionales públicos y particulares debían

inculcar en [los alumnos] el mayor conocimiento posible de nuestros grandes héroes y hombres públicos, y de aquéllos que hayan cimentado su éxito en la disciplina del trabajo y el cumplimiento de su deber. Esta será tarea principal de los profesores de Ciencias Sociales, Orientadores y Jefes de Curso, que deberán desarrollar actividades especiales tendientes a promover y estimular los sentimientos y valores humanos y espirituales de auténtica chilenidad. ${ }^{36}$

Es importante destacar que la Junta Militar incluyó otros temas para ser enseñados en las escuelas, los cuales tenían como finalidad concientizar a los estudiantes con la realidad económica del país, reforzar el

36 Ministerio de Educación Pública, Orden Ministerial Permanente no. 1, 1973, p. 2. 
sentimiento patrio mediante el aprendizaje de la historia nacional ${ }^{37} \mathrm{y}$ revalorizar el rol de la mujer en el hogar. ${ }^{38} \mathrm{~A}$ estas acciones, es fundamental agregar la censura a determinados libros de textos que no se ajustaban a las orientaciones de la dictadura. A través de diversas Circulares $^{39}$ las autoridades ministeriales daban a conocer la prohibición de utilizar textos de estudios que no contaban con la autorización de la Superintendencia de Educación y, anualmente, esta institución entregaba una lista en la cual se detallaban los libros que podían ser usados como materiales auxiliares en las aulas, para evitar que los profesores se guiaran por otros textos en el proceso de enseñanza.

El proceso de depuración de los programas que orientaban la enseñanza en las escuelas chilenas finalmente desembocó en una ideologización de los contenidos. Frente a la ausencia de un proyecto pedagógico, la dictadura llevó a cabo un "vaciamiento de contenidos socialmente significativos», ${ }^{40}$ sobrecargando los programas vigentes con nociones patrióticas y tópicos nacionalistas, en base a los cuales estructuraron hábitos y prácticas en la escuela en los años siguientes.

El análisis de las circulares enviadas por el Ministerio de Educación a los jefes de establecimientos educativos permite evidenciar la directa relación existente entre la orientación patriótica de los contenidos, la

\footnotetext{
$37 \mathrm{Al}$ respecto, es fundamental señalar la Circular no. 846, emitida el 1 de enero de 1979 por el Ministerio de Educación, la cual establecía una serie de contenidos que debían ser enseñados durante el mes de mayo en todas las escuelas y liceos del país, en las asignaturas de Castellano e Historia. En ésta se indicaban los libros que debían utilizarse, entre los cuales figuraban los títulos «Episodios navales chilenos», «Vida de Arturo Prat», «Monitor Huáscar», «Resumen de la Guerra del Pacífico de Gonzalo Bulnes».

38 Mediante la Circular no. 96, del 20 de agosto de 1974, el Ministerio de Educación instaba a los jefes de establecimiento educacionales la importancia de desarrollar una guía de trabajo titulada «La Mujer y la Familia» en $3 .^{\circ}$ y $4 .^{\circ}$ años de Enseñanza Media, la cual tenía como objetivo revalorizar «el rol de la mujer en el hogar como hija, madre y dueña de casa, y tomar conciencia del valor, obligaciones y derechos de la niña y de la adolescente en el hogar».

39 Ministerio de Educación, Subsecretaría de Educación, Circular no. 34, 5 de abril de 1974; Ministerio de Educación, Subsecretaría de Educación, Circular no. 23, 15 de marzo de 1974.

40 Una parte importante de la historiografía argentina sobre educación versa sobre los cambios en el currículum en el período de la dictadura militar encabezada por Videla (1976-1983). De acuerdo con el concepto acuñado por Daniel Filmus, la Junta Militar lleva a cabo un 'vaciamiento de los contenidos socialmente significativos' -noción que perfectamente puede ser aplicada a lo sucedido en el primer período de la dictadura de Pinochet-, eliminando aquellas temáticas relativas a formar una conciencia social en los estudiantes y socializando a niños y jóvenes de manera autoritaria y jerarquizada. En: Daniel Filmus y Graciela Frigeiro, Educación, autoritarismo y democracia (Argentina: Miño y Dávila, 1988), 19.
} 
jerarquía en la relación pedagógica y la utilización de la memorización como principal método de aprendizaje.

\section{LA EXPERIENCIA EDUCATIVA EN CONTEXTO AUTORITARIO}

La vida en las escuelas fue un foco de especial atención para las nuevas autoridades educativas impuestas por la dictadura. La escuela, en tanto espacio formativo para estudiantes y espacio laboral para docentes, fue objeto de intensas regulaciones que buscaban estructurar su funcionamiento en base a los criterios de disciplinamiento y control. En esta sección se revisa cómo las autoridades escolares optaron por valorizar la vigilancia y sanción de la conducta de los actores educativos a través de diversos dispositivos, tales como la intensificación y actualización de rituales escolares que perseguían desarrollar el espíritu patriótico como foco formativo fundamental de las nuevas generaciones. ${ }^{41}$

\section{La cotidianeidad de las escuelas: jerarquía, disciplinamiento y control}

La aplicación de medidas disciplinarias y correctivas en escuelas y liceos fue intensa una vez ocurrido el Golpe Militar. A los pocos días de reiniciadas las clases, el periódico El Mercurio dio a conocer a la población recomendaciones en materia de orden y disciplina escolar, respecto a las disposiciones establecidas por el Ministerio de Educación Pública:

Una vez que la situación general del país experimentó modificaciones sustanciales, a contar del 11 de septiembre, ha correspondido a las autoridades del Ministerio de Educación Pública

\footnotetext{
${ }_{41}$ Estas iniciativas desarrolladas al interior del sistema escolar se inscriben en un proceso mayor de intervención de la dictadura civil militar en la vida cotidiana de la población chilena que ha sido caracterizada como "golpe estético-cultural» por parte de Luis Hernán Errázuriz, quien señala que con posterioridad al Golpe de Estado del 11 de septiembre de 1973 se desarrolló, por parte de las nuevas autoridades, la denominada «operación limpieza» a lo largo y ancho del país, que consistía fundamentalmente en la eliminación de todo vestigio material asociado al marxismo y al Gobierno de la Unidad Popular, al mismo tiempo de la promoción de una estética cotidiana de orientación castrense vinculada a la limpieza, orden y patriotismo. En este orden de cosas, la estética juvenil fue reprimida a través de diferentes vías, tales como la imposición del pelo corto como norma aceptable en el caso de los hombres, la exclusión de los colores rojo y negro en las vestimentas y la exclusión de la canción comprometida de los espacios públicos, entre otras. Ver: Luis Hernán Errázuriz, «Dictadura militar en Chile. Antecedentes del golpe estético-cultural», Latin American Research Review 44, no. 2 (2009): 136-157. https://www.jstor.org/stable/40783610
} 
instruir a la comunidad escolar chilena de conformidad con los nuevos cánones en vigencia [...] Algunas [normas] inciden en una decorosa presentación personal, como acontece en la enseñanza media de la mayoría de las naciones [...] Las recomendaciones sobre respeto, cortesía, modales correctos y lenguaje adecuado revisten asimismo importancia. ${ }^{42}$

Asimismo, durante 1974 la Dirección de Educación Secundaria estableció y recalcó una serie de reglas escolares, tendientes a normalizar la actividad en las escuelas y liceos. Estas decían relación con un correcto uso del uniforme obligatorio, el respeto hacia las nuevas autoridades, la puntualidad en la asistencia a clases y una adecuada utilización del vocabulario. La Circular no. 79, enviada en julio de 1974 por la Dirección de Educación Secundaria a liceos fiscales y colegios particulares del país, recalcaba nuevamente la obligatoriedad de aplicar medidas disciplinarias a los alumnos que transgredieran las normas establecidas en el Reglamento General de Liceos. Al respecto, la Circular determinaba que «A los alumnos que no cumplan dichas normas se les aplicarán medidas disciplinarias [...] que constituyen experiencias positivas que contribuyen eficazmente a la formación de la personalidad del alumno». De acuerdo con el documento, tres comportamientos que parecían conflictivos en los establecimientos educacionales se rectificarían permanentemente: atrasos, inasistencias y actos de indisciplina. Sobre los atrasos, la Circular indicaba que no era conveniente que los escolares fueran devueltos a sus hogares, aconsejando "promover actividades que vayan en beneficio del aseo, del orden o hermoseamiento del local escolar y mantener a los jóvenes rezagados ocupando sus energías en estos menesteres hasta que se integren en la segunda hora de clases». Asimismo, para controlar las inasistencias de los estudiantes -y evitar las «cimarras»-se recomendaba «que tanto la inspección general como los profesores jefes mantengan un registro de firmas de apoderados para comprobar la autenticidad de los justificativos», ${ }^{43}$ con el objetivo de controlar a aquellos estudiantes que reiteradamente no iban a clases.

El disciplinamiento constituyó una dimensión central en la realidad cotidiana de las escuelas después del Golpe. La vigilancia permanente

42 «Recomendaciones sobre normas escolares», El Mercurio, 16 de octubre, 1973.

43 Dirección de Educación Secundaria, Circular no. 79, 4 de julio de 1974, p. 1. 
sobre el comportamiento de los estudiantes se recuperó como práctica al interior de las escuelas, reimpulsando formas de educar que habían sido objeto de transformación en los gobiernos de Frei Montalva y de Salvador Allende. Siguiendo a Lechner, el autoritarismo ${ }^{44}$ de las prácticas pedagógicas era parte de una tradición educativa, enraizado en la fundación del sistema escolar. Si bien en el trascurso del siglo XX se registraron esfuerzos por intentar cambiar los modos de educar a niños y jóvenes (paulatinamente disminuyeron los castigos físicos, pero no se eliminaron completamente) y se cuestionó fuertemente el autoritarismo de los profesores, las relaciones pedagógicas no cambiaron sustancialmente. 45

Si durante los gobiernos reformistas de Frei Montalva y Salvador Allende fue promovida una relación horizontal entre profesores y estudiantes, ${ }^{46}$ en la primera etapa de la dictadura predominó la verticalidad de las relaciones sociales en el aula y un fuerte disciplinamiento en base a castigos. Cualquier comportamiento fuera de lo estipulado implicaba que los estudiantes serían sancionados, con el fin de corregir prácticas que no estaban permitidas. Incluso, la Directora de Educación Secundaria señaló en 1974 su preocupación debido al considerable número de cancelaciones de matrículas escolares, "a veces, masiva, con que algunos establecimientos sancionan al alumnado. Se hace necesario recordar que tanto la matrícula condicional como la cancelación de matrícula se pueden

44 Para conocer las formas en que se ha estudiado el autoritarismo en educación durante la Dictadura civil militar en Chile se recomienda consultar, entre otros, los siguientes trabajos: José Joaquín Brunner, El diseño autoritario de la educación en Chile (Santiago: FLACSO, 1979); Abraham Magendzo, Alejandro Jara, Guillermo Briones y Loreto Egaña, Desigualdad educativa en Chile (Santiago: PIIE, 1980); Norbert Lechner, La vida cotidiana en Chile: la experiencia escolar (Santiago: FLACSO, 1982); Hernán Pozo, Orientación cultural y educacional chilena: 1973-1981 (Santiago: CIDE, 1982); Brunner, La cultura autoritaria; José Joaquín Brunner, Cultura autoritaria y cultura escolar (Santiago: FLACSO, 1984); Programa Interdisciplinario, Las Transformaciones Educacionales; José Joaquín Brunner y Gonzalo Catalán, Cinco estudios sobre cultura y sociedad (Santiago: FLACSO, 1985); José Weinstein y Juan Eduardo García-Huidobro, Entre la ausencia y el acoso. Apuntes bibliográficos sobre jóvenes pobladores, vida cotidiana y Estado en Chile hoy (Santiago: CIDE, 1989); Cristián Cox, Politicas educacionales y principios culturales: Chile 1965-1985 (Santiago: CIDE, 1989); Cristián Cox, Sociedad y conocimiento en los 90. Puntos para una agenda sobre currículo del sistema escolar (Santiago: FLACSO, 1991).

45 Norbert Lechner, La vida cotidiana en Chile: la experiencia escolar (Santiago: FLACSO, 1982), 13.

46 Cristián Bellei y Camila Pérez Navarro, «Democratizar y tecnificar la educación. La reforma educacional de Eduardo Frei Montalva», en Eduardo Frei Montalva: un gobierno reformista. A 50 años de la 'Revolución en Libertad', editado por Carlos Huneeus y Javier Couso (Santiago: Editorial Universitaria, 2016), 207-242; Iván Núñez, La ENU entre dos siglos (Santiago: LOM, 2003). 
adoptar por causas de "suma gravedad", y se aplican sólo después de haber oído el Consejo de Profesores».47

A través de sucesivas informaciones enviadas a las escuelas y liceos, se ordenó a los directores realizar una fiscalización permanente a estudiantes y profesores, con el objetivo de asegurar que cumplieran con las normas establecidas, y sancionar a aquellas personas que no lo hicieran. De acuerdo con la citada circular del Comando de Institutos Militares, los directores debían «Exigir en forma perentoria y permanente, tanto a docentes como educandos, la puntualidad y la presentación personal y el uso correcto de las tenidas». ${ }^{48}$

\section{La intensificación de los rituales escolares}

Si bien la ritualización cívica y religiosa de la experiencia educativa tiene raíces tan profundas como la fundación del sistema escolar, en la dictadura los rituales escolares se intensificaron considerablemente, marcando y estructurando los tiempos de la escuela. Pocos días después del Golpe, la Orden Ministerial Permanente no. 1 estableció que todos los establecimientos públicos y particulares debían iniciar cada semana lectiva con un acto cívico de homenaje a la bandera, «la que se izará en un sitio de honor, destacando algún nombre, hecho o circunstancia que enaltezca el sentimiento de patria y desarrolle, en los alumnos, el orgullo de la chilenidad». Asimismo, la Orden Ministerial determinaba que en cada finalización del período escolar se debían realizar actos solemnes, en donde se destacaran los valores patrios y «rendirse un homenaje especial a la bandera, la que se izará en un sitio público y de honor al son del Himno Nacional, cantado por todos los profesores y alumnos, y en lo posible, con la concurrencia de bandas militares».49 Complementaria a la Orden Ministerial no. 1, y mediante la difusión de la Circular no. 5, el Ministerio de Educación Pública reiteraba al inicio del nuevo año lectivo el estricto cumplimiento de las normas tendientes a estimular el sentimiento patrio en los alumnos de enseñanza fiscal y particular. De

\footnotetext{
47 Dirección de Educación Secundaria, Circular no. 79, p. 2.

48 Ejército de Chile, Circular para regular, p. 4.

49 Ministerio de Educación Pública, Orden Ministerial, p. 2.
} 
acuerdo con el documento, todos los colegios y liceos del país debían realizar la siguiente rutina:

1. Al iniciarse la semana de labores se realizará un acto cívico con participación de la totalidad de los profesores y alumnos, donde se rinde homenaje a la bandera entonando el Himno Patrio, el que debe incluir las dos estrofas que siguen al Coro (5 y 3).

El pabellón debe ser izado con participación de dos alumnos y revestir el máximo de solemnidad.

2. Aquellos establecimientos que funcionan en dos jornadas, al término de la $1 .^{\circ}$, dos alumnos en presencia de un profesor bajarán el pabellón y se dejará sobre una mesa o silla, para ser izado por los alumnos de la segunda jornada.

3. Una vez izado el pabellón, un profesor designado oportunamente por la Dirección del Establecimiento, disertará en forma breve en relación con hechos históricos, personajes ilustres de nuestra nacionalidad. ${ }^{50}$

Adicionalmente, y a través de una Circular emitida dos días después del documento recién citado, se ordenaba a los profesores enseñar a todos los alumnos las estrofas no. 3 y 5 del Himno Nacional, y se reiteraba la obligación de cantar ambas estrofas en el homenaje realizado al inicio de cada semana lectiva:

1) Los Departamentos de Castellano y de Educación Musical, pondrán énfasis en el aprendizaje de las estrofas $\mathrm{N}{ }^{\circ} 3$ y 5 , además del coro, de la Canción Nacional. 2) En la interpretación musical, se cantará primero la estrofa $\mathrm{N}^{\circ}{ }^{\circ}$, como es habitual, y en segundo lugar la estrofa $\mathrm{N} .{ }^{\circ} 3$, seguidas cada una de ellas por el coro, conforme a la versión entregada por la Asesoría de Educación Musical de esta Dirección Secundaria. 3) En caso de cantarse con acompañamiento instrumental, los diez compases introductorios deberán ser ejecutados sólo una vez, para iniciar la primera estrofa, y los compases de conclusión, sólo una vez como final. ${ }^{51}$

\footnotetext{
50 Ministerio de Educación Pública, Circular no. 5, 2 de abril de 1974, p. 1.

51 Ministerio de Educación, Circular no. 32, p. 1.
} 
El cumplimiento de la Orden Ministerial en los establecimientos educacionales decía relación con la facultad del Comando de Institutos Militares de fiscalizar que se efectuara el homenaje en los establecimientos educacionales. De acuerdo con la Circular emitida en agosto de 1974, el Ejército tenía la atribución de «Controlar imprevistamente las disposiciones que han emanado de la Superioridad Militar, en relación con el izamiento de la Bandera Nacional, los días Lunes de cada semana, al mismo tiempo que hacer efectivas las responsabilidades que hubiere por incumplimiento, distorsión o mala ejecución de los detalles».52

Posteriormente, el Decreto no. 29 -publicado el día 22 de febrero de 1975 en el Diario Oficial- reafirmó las disposiciones sobre el enaltecimiento de los valores patrios, y actualizó normas que debían cumplir profesores, estudiantes y paradocentes en las escuelas. De acuerdo con el documento, todos los miembros de la comunidad escolar «quedan obligados a escuchar el Himno Nacional descubiertos, en riguroso silencio y en posición "firme" ». Asimismo, se estableció la prohibición terminante de "exhibir la bandera nacional enlazada con otras banderas o símbolos», y «el uso de insignias o distintivos que representen ideologías políticas nacionales o extranjeras». ${ }^{53}$ Es importante señalar que el decreto determinaba una serie de disposiciones especiales para las escuelas particulares, como por ejemplo, «impartir enseñanza sistemática en español», «designar como profesores de español e historia y geografía a maestros de nacionalidad chilena», "tener una bandera y escudos nacionales», "abstenerse de exhibir [...] símbolos, escudos o banderas foráneas, retratos o efigies de gobernantes extranjeros» $\mathrm{y}$ «solicitar un permiso especial [...] para conmemorar cualquiera efeméride extranjera».54 Finalmente, se estableció la colocación en sitio de honor el retrato del Jefe Supremo del Gobierno de Chile.

Consecuentemente con lo anterior, las Circulares no. 849 y no. 850 -emitidas por la Dirección de Educación el día 1 de enero de 1979- establecían nuevas disposiciones para llevar a cabo el homenaje a la bandera. Mientras que en la primera Circular se impartían las normas sobre la

\footnotetext{
52 Ejército de Chile, Circular para regular, p. 5.

53 Ministerio de Educación Pública, Decreto no. 29, 22 de febrero de 1975, p. 1.

54 Ministerio de Educación Pública, Decreto no. 29, p. 2.
} 
interpretación del Himno -«correcta pronunciación, modulación, vocabulario y memorización» y corrección de «aquella pronunciación defectuosa en los educandos»-;55 en la segunda se solicitaba una correcta presentación personal de los estudiantes que encabezaban el acto y a la solicitud de extrema solemnidad que debía envolver el evento de cada lunes:

Para el izamiento del Pabellón Nacional se seleccionará a dos alumnos de los cursos superiores (Colegios mixtos, uno de cada sexo). Estos izadores deberán saber muy bien el momento que se inicia el izamiento y cuándo la bandera debe estar en el tope del mástil. (Iniciación justo con el primer verso del Himno Nacional y su término justo con el último verso del coro, cantado por segunda vez). En la selección de estos alumnos deberá considerarse su presentación personal (uniforme correcto, corte de pelo, aseo personal y de su vestuario), prestancia personal (garbo), seriedad y ellos deben estar compenetrados de su responsabilidad y de la distinción de que han sido objeto. ${ }^{56}$

La realización de estos ritos en los establecimientos educacionales fue fuertemente controlada por el Ejército en este primer período de la dictadura. Iniciada la década de 1980, la situación en las escuelas paulatinamente va dando paso a un relajamiento de las prácticas, debido a la disminución en el número de fiscalizaciones y a la coyuntura política que lentamente va configurando el término del régimen.

\section{CONCLUSIONES}

El presente trabajo analizó los cambios promovidos en escuelas y liceos chilenos durante la dictadura. Con base en el análisis de las circulares enviadas por el Ministerio de Educación Pública a los liceos, se mostraron los alcances de las acciones y políticas educativas impulsadas por las nuevas autoridades de facto con posterioridad al Golpe de

\footnotetext{
55 Ministerio de Educación, Dirección de Educación, Circular no. 849, 1 de enero de 1979, p. 2.

56 Ministerio de Educación, Subsecretaría de Educación, Circular no. 850, 1 de enero de 1979. Posteriormente, en abril de 1983, la Circular no. 606 reemplazó a la Circular no. 850 «la que deberá ser destruida». En ésta se impartían instrucciones similares relativas a los actos cívicos y a la conmemoración de efemérides.
} 
Estado. Estas acciones se orientaron a intervenir los establecimientos educativos en tres ámbitos principales: en la vida cotidiana escolar, mediante la incorporación e intensificación de nuevos ritos cívicos y religiosos; en la depuración e ideologización de los planes y programas educativos, y en las prácticas pedagógicas, a través del abordaje verticalista de la relación entre docentes y estudiantes.

La persistencia de estas prácticas, incluso bien entrado el siglo XXI, dan cuenta que el impacto de la dictadura no solo se relacionó con las reformas de la arquitectura institucional del sistema educativo, sino también con los sentidos, prácticas y valores adquiridos y promovidos por los diversos actores educativos.

En términos generales, a la luz de los resultados alcanzados es posible sostener que la dictadura le asignó un alto valor a la tarea de configurar un tipo particular de experiencia que debían vivir docentes y estudiantes en la institución escolar, puesto que el volumen y especificidad de las intervenciones analizadas invitan a plantear que las mismas supusieron un complejo proceso de planificación en diferentes niveles y sentidos debidamente articulados y constantemente evaluados en sus resultados.

También es posible sostener que la especificidad de las intervenciones del régimen en la experiencia escolar buscaba como gran objetivo la construcción de una nueva sensibilidad que orientara el pensamiento y la actuación de las y los actores educativos, sensibilidad constituida por la compleja articulación de elementos tales como el antimarxismo, la negación de la dimensión política, la exaltación del patriotismo y la valoración del autoritarismo.

De forma interesante, la intervención sobre la experiencia escolar no se articuló sobre herramientas totalmente novedosas, sino que se desarrolló un interesante proceso de actualización de algunas dimensiones conservadoras de larga existencia en el paisaje escolar chileno, entre las que es posible mencionar al autoritarismo, el nacionalismo y a las metodologías expositivas en tanto alternativas de organización de las relaciones humanas y pedagógicas al interior de la escuela.

A partir de estas conclusiones, es posible afirmar la necesidad de avanzar en futuras investigaciones que permitan aumentar nuestro entendimiento sobre los problemas aquí abordados. Dentro de las proyecciones 
de investigación se visualizan las siguientes: a) estudios sobre las formas específicas en que docentes y estudiantes lidiaron con las intervenciones del régimen autoritario en la experiencia escolar; b) estudios sobre las transformaciones en la construcción y valoración de los textos escolares en las disciplinas centrales del currículum chileno, entendiendo a estos como dispositivos culturales de alto valor en la organización de las relaciones pedagógicas; c) estudios sobre la formación y actuación de los agentes civiles y militares que implementaron las directrices de la dictadura civil militar en la escuela, junto a los posibles éxitos y fracasos en su tarea.

\section{Nota sobre los autores}

Camila Pérez Navarro es doctora en Ciencias de la Educación por la Pontificia Universidad Católica de Chile. Actualmente es investigadora y profesora asistente del Instituto de Ciencias de la Educación de la Universidad de O’Higgins. Sus principales líneas de investigación son: historia de la educación rural, historia de la experimentación pedagógica, e historia reciente de la educación chilena.

Felipe Zurita GarRido es doctor en Educación por la Universidad Federal de Minas Gerais (Brasil). Actualmente es investigador y profesor asociado del Departamento de Educación Básica de la Facultad de Filosofía y Educación de la Universidad Metropolitana de Ciencias de la Educación. Sus áreas principales de investigación son: historia de la educación, políticas educacionales, y enseñanza de la historia y las ciencias sociales.

\section{REFERENCIAS}

Barr-Melej, Patrick. Reforming Chile: Nationalism, and the Rise of the Middle Class. Chapel Hill: University of North Carolina Press, 2001.

Bellei, Cristián y Camila Pérez Navarro, «Democratizar y tecnificar la educación. La reforma educacional de Eduardo Frei Montalva». En Eduardo Frei Montalva: un gobierno reformista. A 50 años de la 'Revolución en Libertad', editado por Carlos Huneeus y Javier Couso, 207-242. Santiago: Editorial Universitaria, 2016. 
Brunner, José Joaquín. El diseño autoritario de la educación en Chile. Santiago: FLACSO, 1979.

Brunner, José Joaquín. La cultura autoritaria en Chile. Santiago: FLACSO, 1982. Brunner, José Joaquín. Cultura autoritaria y cultura escolar. Santiago: FLACSO, 1984.

Brunner, José Joaquín y Gonzalo Catalán. Cinco estudios sobre cultura y sociedad. Santiago: FLACSO, 1985.

Cox, Cristián. Políticas educacionales y principios culturales: Chile 1965-1985. Santiago: CIDE, 1989.

Cox, Cristián. Sociedad y conocimiento en los 90. Puntos para una agenda sobre currículo del sistema escolar. Santiago: FLACSO, 1991.

Errázuriz, Luis Hernán, «Dictadura militar en Chile. Antecedentes del golpe estético-cultural», Latin American Research Review 44, no. 2 (2009): 136157. https://www.jstor.org/stable/40783610

Errázuriz, Javiera. «Control y disciplinamiento de la comunidad estudiantil en los primeros años del régimen militar (1973-1975): Los expedientes de Geografía y Teatro en la Universidad de Chile». Cuadernos Chilenos de Historia de la Educación 8, (2017): 36-56. http://historiadelaeducacion.cl/index.php/ $\mathrm{CCHE} /$ article/view/9

Faunes, Martín. Aulas que permanecerán vacías. Santiago: Cuarto Propio, 2008. Filmus, Daniel y Graciela Frigeiro. Educación, autoritarismo y democracia. Argentina: Miño y Dávila, 1988.

Gomes Ferreira, Antonio y Luís Mota. «Diferentes perspetivas de um ensino conservador: o ensino liceal em Portugal durante o Estado Novo (19361960)». Educar em Revista 30, no. 51 (2014): 145-174. https://doi.org/10.1590/ S0104-40602014000100010

González Miranda, Sergio. Chilenizando a Tunupa. La escuela pública en el Tarapacá andino 1880-1990. Santiago: DIBAM, 2002.

Julia, Dominique. «A Cultura Escolar como Objeto Histórico». Revista Brasileira de História da Educação 1 (2001): 9-43, http://periodicos.uem.br/ojs/index.php/rbhe/article/view/38749.

Kaufmann, Carolina (Dir.). Dictadura y Educación. Tomo I. Universidad y Grupos Académicos (1976-1983). Buenos Aires: Miño y Dávila, 2001.

Kaufmann, Carolina (Dir.). Dictadura y Educación. Tomo II. Depuración y vigilancia en las Universidades Nacionales Argentinas. Buenos Aires: Miño y Dávila, 2003.

Kaufmann Carolina (Dir.). Dictadura y Educación. Tomo III. Los textos escolares en la historia argentina reciente. Buenos Aires: Miño y Dávila, 2006.

Lechner, Norbert. La vida cotidiana en Chile: la experiencia escolar. Santiago: FLACSO, 1982. 
Magalhães Gomes Mota, Carlos Alberto. «A Educação Portuguesa durante o Estado Novo (1933-1974): uma visão de síntese». Saberes Interdisciplinares 13, no. 25 (2020): 33-48. http://186.194.210.79:8090/revistas/index.php/SaberesInterdisciplinares/article/view/340

Magendzo, Abraham, Alejandro Jara, Guillermo Briones y Loreto Egaña. Desigualdad educativa en Chile. Santiago: PIIE, 1980.

Morandini, Maria Cristina. «I quaderni di epoca fascista veicolo di propaganda ideologica e strumento didattico: il fondo della scuola elementare Parini di Torino (1938-1942)». Historia y Memoria de la Educación 10 (2019): 383408. https://doi.org/10.5944/hme.10.2019.23365

Navarro Sandalinas, Ramón y Manuel Tuñón de Lara. La enseñanza primaria durante el franquismo (1936-1975). Barcelona: PPU, 1990.

Núñez, Iván. La ENU entre dos siglos. Santiago: LOM, 2003.

Patto Sá Motta, Rodrigo. As universidades e o regime militar. Cultura politica brasileira e modernização autoritária. Rio de Janeiro: Zahar, 2014.

Pereira, Maria Paula. «A Escola Portuguesa ao serviço do Estado Novo: as Lições de História de Portugal do Boletim do Ensino Primário Oficial e o Projeto Ideológico do Salazarismo». Da Investigação às Práticas 4, no. 1 (2014): 59-81.

Pérez Navarro, Camila. «El control de las escuelas durante la Dictadura Cívico Militar chilena: el caso de la Escuela Experimental de Niñas de Santiago». Anuario de Historia de la Educación 18, no. 2 (2017): 5-25.

Pérez Navarro, Camila. «La intervención de las escuelas durante las dictaduras cívico-militares en el Cono Sur. Miradas desde la historia de la educación». En Latinoamérica: la educación y su historia. Nuevos enfoques para su debate y enseñanza, coordinado por Nicolás Arata y Pablo Pineau, 423-449. Buenos Aires: Editorial de la Facultad de Filosofía y Letras, UBA, 2019.

Pérez, Camila y Andrés Rojas-Murphy. «Introducción y consolidación de los principios de mercado en el discurso oficial sobre educación de la dictadura civil militar chilena (1973-1990)». Paulo Freire. Revista de Pedagogía Crítica 20 (2019): 105-122. https://doi.org/10.25074/07195532.20.1089

Pineau, Pablo, Marcelo Mariño, Nicolás Arata y Belén Mercado. El principio del Fin. Políticas y Memorias de la educación en la última dictadura militar (1976-1983). Buenos Aires: Editorial Colihue, 2006.

Pineau, Pablo. «Reprimir y discriminar. La educación en la última dictadura cívico-militar en Argentina (1976-1983)». Educar em Revista 30, no. 51 (2014): 103-122. https://doi.org/10.1590/S0104-40602014000100008

Pozo, Hernán. Orientación cultural y educacional chilena: 1973-1981. Santiago: CIDE, 1982.

Programa Interdisciplinario de Investigación en Educación. Las Transformaciones Educacionales bajo el Régimen Militar, 2 volúmenes. Santiago: PIIE, 1984. 
Reyes, Leonora. «Movimientos de educadores y construcción de política educacional en Chile». Tesis para optar al grado de doctora en Historia, Universidad de Chile, 2005.

Rinke, Stefan. Cultura de masas, reforma y nacionalismo en Chile 1910-1931. Santiago: DIBAM, 2002.

Rinke, Stefan. Encuentros con el Yanqui. Norteamericanización y cambio sociocultural en Chile (1898-1990). Santiago: DIBAM/LOM, 2014.

Rojas Flores, Jorge. Moral y prácticas cívicas en los niños chilenos, 1880-1950. Santiago: Ariadna Ediciones, 2004.

Rojas Flores, Jorge. Historia de la infancia en el Chile republicano: 1810-2010. Santiago: JUNJI, 2010.

Ruiz, Carlos. De la República al mercado. Ideas educacionales y política en Chile. Santiago: LOM, 2010.

Sánchez, Pamela. Una asignatura pendiente: profesores y profesoras detenido/as, desparecido/as y ejecutado/as en Chile de 1973 a 1990. Santiago: ARCIS, 2013.

Sanz Simón, Carlos. «Los símbolos del nacionalcatolicismo. Una mirada a través de la fotografía escolar durante la dictadura franquista (1950-1959)». Historia y Memoria de la Educación 10 (2019): 409-449. https://doi.org/10.5944/ hme.10.2019.22194

Sass, Odair, Carlos Antonio Giovinazzo Júnior, Domenica Martinez, Helenice Ciampi, Leda Maria de Oliveira Rodrigues y Maria Amelia Güllnitz Zampronha. Educação e Regimes Ditatoriais: 50 anos do Golpe Militar no Brasil. Araquara: Junqueira\&Marin, 2018.

Saviani, Dermeval. «O legado educacional do regime militar». Cadernos CEDES 28, no. 76 (2008): 291-312. https://dx.doi.org/10.1590/S0101-32622008000300002

Spindola Zago, Octavio. "Hemos hecho Italia, ahora tenemos que hacer a los italianos". El aparato educativo transnacional del régimen fascista italiano, 19221945». Historia mexicana 69, no. 3 (2020): 1189-1246. https://doi.org/10.24201/ hm.v69i3.4021

Taborda de Oliveira, Marcus Aurelio. Educação Física Escolar e Ditadura Civil-Militar no Brasil (1968-1984): Entre a Adesão e a Resistência e Outros Estudos. Curitiba: Editora UFPR, 2018.

Tedesco, Juan Carlos, Cecilia Braslavsky y Ricardo Carciofi. El proyecto educativo autoritario (1976-1982. Buenos Aires: FLACSO, 1985.

Toro-Blanco, Pablo. "Como se quiere a la madre o a la bandera: Notas sobre nacionalismo, ciudadanía y civilidad en la educación chilena (1910-1945)"». En Nacionalismos e identidad nacional en Chile. Siglo XX. Volumen I, editado por Gabriel Cid y Alejandro San Francisco, 133-158. Santiago: Ediciones Bicentenario, 2010.

Toro-Blanco, Pablo. ““iNiños, seamos buenos, miremos ese horror!”. El nacionalismo cívico como régimen emocional en la educación chilena durante la 
segunda guerra mundial (c.1941-c.1945)». Sarmiento. Revista Galego-Portuguesa de Historia da Educación 24 (2020): 161-175. https://doi.org/10.17979/ srgphe.2020.24.0.7132

Toro-Blanco, Pablo. «Towards a new Chile through the heart: aspects on the construction of a nationalist emotionology in school textbooks during Pinochet years (c.1974-c.1984)». History of Education \& Children's Literature X, 1 (2015): 583-600.

Viñao Frago, Antonio. «La educación en el franquismo (1936-1975)». Educar em Revista, 30(51), 19-35. https://doi.org/10.1590/S0104-40602014000100003

Weinstein, José y Juan Eduardo García-Huidobro. Entre la ausencia y el acoso. Apuntes bibliográficos sobre jóvenes pobladores, vida cotidiana y Estado en Chile hoy. Santiago: CIDE, 1989.

Yanes Mesa, Julio Antonio. «La propaganda, el entretenimiento y la educación en los espacios infantiles de la radiodifusión de las Islas Canarias durante el franquismo, 1939-1975». Historia y Memoria de la Educación 4 (2016): 371392. https://doi.org/10.5944/hme.4.2016.16226

Zurita, Felipe. «El trabajo docente bajo sospecha los límites a las prácticas docentes en las Políticas Públicas Educacionales de la Dictadura Cívico Militar en Chile (1973-1990)». Educació i Història: Revista d'Història de l'Educació 35 (2020): 207-227. https://doi.org/10.2436/20.3009.01.243

Zurita, Felipe. «El trabajo docente durante la Dictadura Cívico-Militar en Chile (1973-1990): una mirada desde las políticas públicas educacionales». Revista História da Educação 24 (2020): 1-31. https://doi.org/10.1590/22363459/92711

Zurita, Felipe. «Represión y vigilancia hacia el Trabajo Docente durante la Dictadura Militar en Chile (1973-1990)». Araucaria. Revista Iberoamericana de Filosofía, Política y Humanidades 38 (2017): 285-322. https://doi.org/10.12795/ araucaria.2017.i38.13 